\title{
ANÁLISE DOS CRITÉRIOS UTILIZADOS EM RELAÇÃO AOS ESTOQUES OBSOLETOS EM UMA EMPRESA ATACADISTA
}

\section{ANALYSIS OF THE CRITERIA USED IN RELATION TO OBSOLETE INVENTORY IN A WHOLESALER COMPANY}

\begin{abstract}
RESUMO
Considerando que a gestão e o controle dos estoques são processos fundamentais para organizações que querem seguir competitivas no mercado atual tão concorrido, o presente estudo teve como objetivo conhecer os procedimentos utilizados por uma empresa do ramo atacadista, em relação à provisão de estoques obsoletos, bem como verificar se as regras aplicadas estão de acordo com a legislação vigente. Para tanto, o método de trabalho adotado foi o indutivo-dedutivo, com abordagem quanti-qualitativa, por meio de pesquisa de campo do tipo estudo de caso, empregando como referencial os documentos da própria empresa, além de livros e artigos relevantes à temática. Como resultado, foi possível constatar que o conceito de estoque obsoleto utilizado pela empresa diverge dos conceitos apresentados na literatura e também na legislação contábil. No entanto, não foi possível mensurar os impactos dos estoques obsoletos sobre o resultado, devido à utilização de conceito comercial para apurar o valor para provisão.
\end{abstract}

Palavras chave: Gestão de Estoques. Obsolescência. Provisão.

\begin{abstract}
Considering that inventory management and control are fundamental processes for organizations that want to remain competitive in today's aggressive market, the objective of this study is to know the procedures used by a wholesaler company in relation to the provision of obsolete inventories, as well as to verify if the rules applied are in accordance with the current legislation. Therefore, the work method adopted was the inductive-deductive, with a quantitative-qualitative approach, through a field research of the case study type, using as reference the company's own documents as well as books and articles relevant to the theme. As a result, it was possible to verify that the concept of obsolete inventories used by the company diverge from concepts presented in the literature as well as in the accounting legislation. However, it was not possible to measure the impact of obsolete inventories on the result, due to the use of commercial concept to determine the value for provision.
\end{abstract}

Keywords: Inventory Management. Obsolescence. Provision.

\section{Emerson Amaro Lemes}

Graduado em Administração de Empresas pela Universidade Católica Dom Bosco de Campo Grande/MS (UCDB). Pós-graduado em Controladoria e Gestão Tributária pelo Instituto Nacional de Planejamento e Estudos Tributários (INPET). Contato: Rua Albert Sabin, 1246, Taveirópolis, Campo Grande, MS, CEP: 79090.160. E-mail: emerson.lemes@gmail.com.

\section{Emanoel Marcos Lima}

Doutor e Mestre em Ciências Contábeis pela Faculdade de Economia, Administração e Contabilidade da Universidade de São Paulo. Pós-Graduado em Perícia e Investigação Contábi Financeira Empresarial pelo Instituto Nacional de Pós-graduação em convênio com a Universidade Católica Dom Bosco. Professor adjunto da Universidade Federal de Mato Grosso do Sul (UFMS). Contato: Av. Senador Filinto Muller, 1555, Vila Ipiranga, Campo Grande, MS, CEP: 79074.40. E-mail: emanoel.lima@ufms.br. 


\section{INTRODUÇÃO}

O estoque é um dos ativos mais importantes para a empresa, pois tem uma relevância alta no grupo do ativo circulante e influencia fortemente o resultado. É por meio do estoque que a companhia pode cumprir sua atividade operacional e auferir os resultados esperados. Além disso, o estoque contribui diretamente para a maximização dos resultados e impacta a administração do capital circulante líquido.

Nesse sentido, a gestão e o controle de estoques são fundamentais para uma empresa, sobretudo no ramo atacadista, visto que estão diretamente ligados ao resultado financeiro da organização. Apesar de gerarem alguns custos, como o de manutenção e obtenção, exercem função essencial na realização das receitas.

Uma gestão eficiente dos estoques permite à empresa manter-se competitiva no mercado, uma vez que obtém maior controle sobre os custos e perdas da operação. Se mal administrados, os estoques podem gerar diversas perdas, entre elas: furto/roubo, deterioração, obsolescência, avarias, etc.

Um custo muito comum que ocorre na administração dos estoques é o que advém da obsolescência. Por se tratar de um custo não tão evidente e por não ser de fácil levantamento, muitas vezes, acaba por ser negligenciado.

Em um mercado tão concorrido, em que as margens estão cada vez mais apertadas, o gestor deve ter um controle rigoroso dos seus custos e despesas, pois qualquer descuido pode levá-lo a operar com prejuízo.

Por tais motivos, a presente pesquisa tem como objetivo analisar os critérios adotados pela empresa, em relação à provisão para perda com obsolescência de estoque, verificando se esta se encontra de acordo com a legislação, bem como avaliando o impacto deste item no resultado.

No que diz respeito à relevância, o presente trabalho contribui para ampliar as discussões teórico-empíricas sobre o reconhecimento das perdas com obsolescência de estoque, haja vista poucos estudos no Brasil sobre o tema, possibilitando, dessa forma, o desenvolvimento de futuras pesquisas, principalmente no que diz respeito aos mecanismos utilizados pelas empresas na identificação, mensuração e reconhecimento das perdas com estoques.

Este artigo está estruturado da seguinte forma: além desta introdução, será apresentado um breve referencial teórico sobre o tema, seguido da metodologia utilizada, da apresentação e análise dos resultados, e conclusões finais.

\section{REFERENCIAL TEÓRICO \\ 2.1 A importância dos estoques}

Por meio dos estoques, a empresa alcança um de seus principais objetivos, que consiste no atendimento às necessidades dos clientes. Daí a importância deste item para a administração de um negócio.

Além deste caráter estratégico, Oliveira et al. (2013, p. 129) afiançam que: "Os estoques assumem grande importância no contexto do balanço patrimonial e na Demonstração do Resultado do Exercício, visto que quase sempre os valores investidos nesse item são relevantes".

Por serem tão importantes, os estoques merecem uma atenção especial. "A gestão de ativos e passivos circulantes - é uma das atividades mais importantes e mais intensas do administrador financeiro", ressalta Gitman (2004, p. 510).

Porém, os administradores das empresas enfrentam dificuldades para efetuar uma gestão eficiente dos estoques, o que corrobora as palavras de Martins et al. (2013) ao afirmarem que os estoques envolvem vários problemas, como os de administração, controle, contabilização e, principalmente, avaliação.

Outro problema é que, apesar de haver várias razões a favor dos estoques, entre elas a melhoria do serviço prestado ao cliente e a economia na compra de mercadoria, visto que é possível comprar em maior quantidade, é preciso manter o nível de estoque em valor adequado, sem excessos, uma vez que esta atitude gera diversos custos, como: de capital de giro, de capital, de pedido, de manutenção, de oportunidade e de obsolescência.

Tais custos são elevados, como alerta Ballou (2006, p. 271), ao afirmar que: "O custo de manutenção desses estoques pode representar de 20 a $40 \%$ do seu valor por ano. Por isso mesmo, administrar cuidadosamente o nível dos estoques é economicamente sensato".

Além disso, o gestor deve ficar atento, pois um elevado nível de estoque pode trazer diversos problemas, entre eles: atraso na entrega por parte dos fornecedores; baixa previsibilidade da demanda; e lead time desajustado. De acordo com Tadeu et al. (2010, p. 3), "[...] os elevados níveis de estoque escondem boa parte dos problemas da própria cadeia produtiva".

Devido a estes custos, observa-se que é importante evitar níveis elevados de estoques; mais que isto, é importante realizar os estoques com certa velocidade. "O objetivo da administração de estoques é girá-lo o mais rapidamente possível, sem perder vendas por faltas de estoque.” (GITMAN, 2004, p. 516).

\subsection{Gestão de estoques}

Uma boa gestão de estoques se inicia com o planejamento da demanda, ou seja, com a previsão de vendas. Toda e qualquer empresa que oferta algum tipo de produto ao mercado necessita realizar esta tarefa criteriosamente.

$\mathrm{Na}$ atualidade, com a automação dos pontos de venda e o uso propagado da tecnologia nas empresas, ficou mais fácil obter informação relevante para a tomada de decisão. 
Um indicador importante a ser medido é o giro dos estoques, que está mais ligado ao resultado da companhia. A rotatividade do estoque ou giro indica quantas vezes o estoque foi renovado no ano, calculado da seguinte forma, segundo Dias (2010):

$$
\mathrm{R}=\mathrm{C} / \mathrm{EM}
$$

onde:

$\mathrm{R}=$ rotatividade

$\mathrm{C}=$ consumo expresso em unidades

$\mathrm{EM}=$ estoque médio em unidades.

Visto que as empresas estão buscando, cada vez mais, reduzir seus estoques, devido aos custos envolvidos para mantê-los, trabalhar com um giro continuamente menor aumenta a probabilidade de auferir lucros.

Figueiredo, Fleury e Wanke (2003), Viana (2010) e Arnold (2009) asseveram que uma política de estoque depende de definições claras quanto a quatro questões primordiais, indicadas a seguir.

Quando pedir: uma questão importante é saber em que momento emitir um pedido de reposição. Para Figueiredo, Fleury e Wanke (2003), busca-se determinar se a empresa irá ou não seguir a metodologia sugerida pelo ponto de pedido. Tal sistema depende diretamente do consumo médio de materiais e do lead time de resposta.

Além do sistema do ponto de pedido, Arnold (2009) informa que existem outros dois tipos de sistemas básicos:

1. Sistema de revisão periódica: a quantidade disponível de um item é determinada a intervalos de tempos específicos e fixos, por exemplo, uma semana. O período de revisão é fixo, permitindo que ocorra variação na quantidade do pedido.

2. Material Requirement Planning (MRP): mais voltado para o chão de fábrica, este sistema prevê quando haverá demandas para o suprimento central. Proporciona ao suprimento central e à fábrica a oportunidade de planejar os produtos que realmente serão necessários e quando.

Quanto pedir: busca-se determinar se é mais adequado para uma empresa adotar a metodologia do lote econômico de compras ou implementar um regime de ressuprimento just in time.

Quanto manter em estoque de segurança: estoque de segurança é a quantidade mínima possível capaz de suportar um tempo de ressuprimento superior ao programado ou um consumo desproporcional (VIANA, 2010). Os estoques de segurança são determinados supondo que a variabilidade da demanda siga uma distribuição de probabilidade normal (padrão que demonstra previsibilidade). De acordo com Arnold (2009), a maioria dos padrões de demanda é estável e previsível.

Para Figueiredo, Fleury e Wanke (2003), as variáveis que impactam a determinação do estoque de segurança são: variabilidade da demanda, disponibilidade desejada do produto, custo associado ao excesso e à falta de produtos em estoque.

Onde localizar os estoques na cadeia de suprimentos: é uma decisão de centralizar ou descentralizar os estoques. Para Figueiredo, Fleury e Wanke (2003), as dimensões que influenciam a localização dos estoques na cadeia de suprimentos são: o giro do material, lead time de resposta, nível de disponibilidade exigida pelos mercados e valor agregado do material.

Por vários motivos, entre eles a necessidade de maximizar lucros, diminuir os custos com armazenagem, manutenção, obsolescência, entre outros, as empresas vêm buscando reduzir o nível dos estoques.

Diversos fatores, segundo Figueiredo, Fleury e Wanke (2003), vêm determinando este tipo de política: a diversidade crescente no número de produtos; o elevado custo de oportunidade de capital; e o foco gerencial na redução do Capital Circulante Líquido.

Existem ferramentas na gestão de estoque que podem contribuir para a redução dos estoques, sem provocar falta de produtos para atender os clientes.

Entre tais ferramentas, está o lote econômico de compras. Tal método consiste em calcular o menor custo total para a empresa, considerando os custos de pedir e de manter estoques. Para Accioly, Ayres e Sucupira (2008), o lote econômico é capaz de equilibrar os custos de reposição e de manutenção. O cálculo do lote econômico é feito por meio da seguinte fórmula:

$$
\mathrm{LEC}=\sqrt{\frac{2 * \mathrm{CA} * \mathrm{CC}}{\mathrm{CAP} * \mathrm{PU}}}
$$

onde:

$\mathrm{CC}=$ custo fixo de solicitação de pedido

$\mathrm{CA}=$ Consumo anual em unidades do produto

$\mathrm{CPA}=$ Custo da unidade do produto armazenado

$\mathrm{PU}=$ Preço unitário do produto. 
Apesar das vantagens, este modelo sofre algumas críticas, entre elas o fato de ser pouco sensível às variações nas quantidades do pedido. Outras críticas levam em consideração que a demanda é sempre constante e que o lead time é sempre igual a zero.

Devido às críticas, é importante que tal modelo seja complementado com o uso de outras ferramentas; entre elas uma essencial é o conceito da Curva $\mathrm{ABC}$, que permite identificar os poucos itens que são responsáveis pela maior parte das vendas, conhecido como relação 80-20.

Os itens da curva A merecem um controle maior, ou seja, não podem faltar, pois afetam sobremaneira a venda da empresa. "Os itens A são rotineiramente os mais vendidos, itens B os de vendas médias, e os itens $\mathrm{C}$ aqueles de movimentação lenta.” (BALLOU, 2006, p. 305).

A curva ABC possibilita o uso em diversas áreas. Accioly, Ayres e Sucupira (2008) exemplificam que é possível, com a curva $A B C$, organizar a distribuição dos produtos nas prateleiras e definir a frequência de contagens em inventários cíclicos.

Uma evolução do lote econômico de compras é o Just In Time (JIT). De acordo com Rossetti et al. (2008), é um sistema japonês de produção, cujo conceito é o produto certo, na hora certa, na quantidade certa e no prazo certo. Neste sistema, diminuem-se, sobretudo, os custos de manutenção e armazenamento. Além disso, o estoque é bastante reduzido, uma vez que os fornecedores estão próximos das fábricas.

\subsection{CPC 16}

Segundo o Comitê de Pronunciamentos Contábeis os estoques devem ser mensurados pelo valor de custo ou pelo valor realizável líquido, sendo, entre os dois, o menor. Tal valor deve incluir todos os custos de aquisição e de transformação, bem como outros custos incorridos, para trazer os estoques à sua condição e localização atuais.

Para que seja possível mensurar os estoques, é de suma importância conhecer a definição de custo. Conforme o CPC 16, in verbis:

O custo de aquisição dos estoques compreende o preço de compra, os impostos de importação e outros tributos (exceto os recuperáveis junto ao fisco), bem como os custos de transporte, seguro, manuseio e outros diretamente atribuíveis à aquisição de produtos acabados, materiais e serviços. Descontos comerciais, abatimentos e outros itens semelhantes devem ser deduzidos na determinação do custo de aquisição.

Existem outras formas para a mensuração do custo, que são: o custo-padrão ou método varejo, porém não se aplicando à unidade estudada.

Quanto ao critério de avaliação dos estoques, são permitidos o PEPS (Primeiro a Entrar, Primeiro a Sair) e o custo médio ponderado. O importante é a entidade utilizar o mesmo critério durante o mesmo exercício.

Tal pronunciamento prevê o tratamento a ser dado ao custo dos estoques, quando estes se tornam obsoletos:

O custo dos estoques pode não ser recuperável se esses estoques estiverem danificados, se se tornarem total ou parcialmente obsoletos ou se os preços de venda tiverem diminuído. O custo dos estoques pode também não ser recuperável se os custos estimados de acabamento ou os custos estimados a serem incorridos para realizar a venda tiverem aumentado. A prática de reduzir o valor de custo dos estoques (write down) para o valor realizável líquido é consistente com o ponto de vista de que os ativos não devem ser escriturados por quantias superiores àquelas que se espera que sejam realizadas com a sua venda ou uso (grifos nossos).

Conforme prevê este pronunciamento, em cada período subsequente, deve ser feita uma nova avaliação do valor realizável líquido. Quando as circunstâncias que, anteriormente, provocaram a redução dos estoques abaixo do custo deixarem de existir ou quando houver uma clara evidência de um aumento no valor realizável líquido, devido à alteração nas circunstâncias econômicas, a quantia da redução deve ser revertida (a reversão é limitada à quantia da redução original), de modo a que o novo montante registrado do estoque seja o menor valor entre o custo e o valor realizável líquido revisto.

De acordo com este pronunciamento, quando os estoques são vendidos, o custo escriturado desses itens deve ser reconhecido como despesa do período em que a respectiva receita é reconhecida. A quantia de qualquer redução dos estoques para o valor realizável líquido e todas as perdas de estoques devem ser reconhecidas como despesa do período em que a redução ou a perda ocorrerem. A quantia de toda reversão de redução de estoques, proveniente de aumento no valor realizável líquido, deve ser registrada como redução do item em que for reconhecida a despesa ou a perda, no período em que a reversão ocorrer.

\subsection{A obsolescência dos estoques}

Muitas vezes os gestores confundem o conceito de obsolescência dos estoques com itens de baixo giro ou itens danificados. 
A definição do dicionário Houaiss para a palavra obsoleto refere que "é o que já não se usa; arcaico; fora de moda; ultrapassado" (HOUAISS; VILLAR, 2004, p. 527). Mesma definição é dada por Femenick (2011, p. 131, grifos nossos): "[...] identificam-se como obsoletos aqueles itens que perdem as condições de uso por serem arcaicos, antigos, fora de moda, ultrapassados. A obsolescência representa a perda do valor da matéria-prima ou do produto, em decorrência de uma mudança no modelo, no estilo".

Quando o design ou as especificações do ativo não cumprem mais as funções para as quais ele foi projetado (ou pretendido) originalmente, tem-se a obsolescência funcional, esclarece Catti (2013).

A obsolescência funcional pode ser causada por diversos fatores. Segundo Barreca (1999 apud CATTI, 2013, p. 37), os fatores que podem causar a obsolescência funcional são: mudanças regulatórias e legislativas; maior concorrência; mudanças na demanda e nas expectativas do mercado; maior eficiência de novos equipamentos; preços menores para novos equipamentos; maior funcionalidade de reposição; maior capacidade de novos produtos; e outras mudanças técnicas.

O marketing pode colaborar com o aumento da obsolescência dos estoques. O marketing agressivo é responsável por aguçar os desejos dos consumidores e, por consequência, aumentar a taxa de perecibilidade dos produtos, segundo o professor Femenick (2011).

No que diz respeito à obsolescência dos produtos, pode ser propositadamente forçada. O documentário The Light Bulb Conspiracy (2016), da diretora Cosima Dannoritzer, mostra como surgiu o conceito. Nele é demonstrado como os produtos feitos para durar menos, um padrão que começou com a Revolução Industrial, contribuíram para aumentar as vendas. Mais tarde, na década de 1950, o conceito ressurgiu com o enfoque de criar a necessidade no consumidor para que ele consumisse algo novo. Com a ajuda do design e do marketing, seduzia o consumidor para que desejasse sempre o último modelo.

Adotando uma visão mercadológica, o professor Zuffo (2004, p. 215) define a diferença entre os diversos tipos de obsolescência:

a) obsolescência programada de seus produtos, quer pela qualidade, quer pelo tempo de vida média-curto de determinado produto: considerada uma estratégia arriscada para imagem de uma marca, esta linha de atuação, por falta de conhecimentos tecnológicos, ou mesmo intencionais, coloca no mercado produtos para operar razoavelmente bem por determinado período de tempo; b) obsolescência de seus produtos pelos modismos e pela desatualização: neste tipo de política, vende-se ao consumidor a ideia da necessidade de aquisição de um novo bem, diante do fato do bem por ele possuído ou estar fora de moda ou estar desatualizado. Desta forma a indústria incentiva enormemente o consumo; c) obsolescência tecnológica: ocorre naturalmente em decorrência da evolução tecnológica em muitos campos da atividade humana. Esta situação faz com que o consumidor esteja sempre ansioso por possuir a última palavra na linha de produtos; d) incentivo ao consumo de produtos em termos de status social: normalmente não se destina a grandes massas. O nome e a marca são fundamentais, ocupando segundo lugar a qualidade do produto. O mercado existe em função do esnobismo e da excentricidade da classe dominante.

Tão importante quanto conhecer o conceito de obsolescência dos estoques é conhecer os custos envolvidos. Para Bowersox, Closs e Cooper (2007, p. 149): "Os custos de obsolescência derivam da deterioração dos produtos durante a armazenagem. [...] A obsolescência também envolve perda financeira quando um produto se torna obsoleto em termos de moda ou pelo fato de o projeto estar ultrapassado".

Um dos problemas está no controle e gestão da perda de estoque, da qual a obsolescência faz parte. Segundo Pozo (2004), um dos objetivos do planejamento e controle de estoque é a identificação e eliminação dos itens obsoletos e defeituosos.

Para que este valor seja considerado no balanço patrimonial, lança-se mão de uma provisão. Martins et al. (2013) lembram que:

A conta provisão para perdas em estoques destina-se a registrar as perdas conhecidas em estoques e calculadas por estimativa, relativas a estoques morosos ou obsoletos e, mesmo, para dar cobertura a diferenças físicas, quando tais perdas não puderem ser baixadas das próprias contas, pelo fato de não estarem identificados os itens específicos e por constituírem estimativas (MARTINS et al., 2013, p. 118).

O controle sobre os itens obsoletos não é tarefa fácil, porque depende de um rigoroso sistema de controle interno. Martins et al. (2013) complementam que:

No caso de estoques obsoletos ou morosos, novamente, torna-se bastante difícil, na prática, o cálculo da perda item a item, podendo-se efetuar alternativamente uma provisão baseada num percentual que seja adequado para a finalidade, e que seria aplicado sobre o valor total com que tais estoques estão contabilizados, caso em que tal provisão não seria dedutível para fins fiscais (MARTINS et al., 2013, p. 129). 
É possível levantar o custo com a obsolescência dos estoques por meio de um histórico registrado na empresa. De acordo com Bowersox, Closs e Cooper (2007, p. 149): "Os custos de obsolescência normalmente são estimados com base na experiência anterior relacionada a remarcações de preço, doações ou quantidade destruída. Essa despesa representa o percentual do valor do estoque médio declarado obsoleto a cada ano".

A empresa que possui um sistema de controle interno é capaz de identificar os materiais que estão na situação de sucatas, obsoletos ou inservíveis. Após a identificação, será capaz de descartar com precisão os materiais que não têm condições de ser vendidos, contribuindo inclusive para redução de custos de armazenagem e manutenção.

Os objetivos em descartar tais materiais são apresentados por Viana (2010, p. 130): "[...] eliminar os materiais que não mais atendam às exigências técnicas da empresa; desocupar áreas de armazenagem; reduzir os custos de armazenamento e reduzir o valor das imobilizações em materiais".

Com o objetivo de facilitar a identificação e melhorar o controle dos materiais considerados inservíveis, Viana (2010) sugere segregá-los no estoque, por meio das seguintes denominações: materiais a serem beneficiados; sucata; venda; e utilizar até esgotar.

\section{METODOLOGIA}

Visando atingir os objetivos propostos, esta pesquisa adotará diversos procedimentos metodológicos, necessários para o desenvolvimento da investigação e elaboração do trabalho.

Com este estudo, pretende-se realizar uma pesquisa que prime pela compreensão e conhecimento dos procedimentos adotados por um centro de distribuição, para reconhecimento dos estoques obsoletos.

Entende-se que este estudo possibilitará 'desenhar um retrato' do cotidiano da empresa pesquisada, para que, assim, seja possível criar mecanismos de reconstrução da prática utilizada.

O estudo desenrolou-se em um centro de distribuição, cuja identidade não será revelada, porém os números apresentados são reais. Tal estudo foi autorizado pela diretoria da empresa e a coleta de dados foi realizada por meio de visitas ao local no período de 01/06/2016 a 30/09/2016. Também foram efetuadas entrevistas com os responsáveis pelo estoque e contabilidade, para conhecer os procedimentos utilizados pela empresa no controle, identificação, mensuração e reconhecimento das perdas nos estoques.

O trabalho foi desenvolvido utilizando-se as seguintes técnicas: pesquisa bibliográfica, pesquisa documental, entrevistas e análise de dados contábeis. Sendo assim, caracteriza-se este estudo, de acordo com Martins e Theóphilo (2007, p. 59), como pesquisa quase-experimental; segundo os autores, “[...] a estratégia de pesquisa ex post facto é a mais comum das investigações sobre o 'mundo' das Ciências Sociais Aplicadas”. Ou seja, os estudos visam à relação entre as variáveis cujos delineamentos ocorrem após os fatos.

Esta pesquisa caracteriza-se como teórico-empírica, pois, segundo Demo (1985, p. 8), “[...] aquela produção científica que busca conhecer a realidade, incluindo neste ato um trabalho teórico e um trabalho empírico”. Sendo assim, a pesquisa se apoiará no referencial teórico para realizar os confrontos com a realidade estudada.

A interpretação dos dados foi feita mediante a análise documental e confrontação com a legislação vigente e literatura sobre o tema.

\section{APRESENTAÇÃO E ANÁLISE DOS RESULTADOS 4.1 A empresa}

O atacadista compra produtos em grande quantidade do fabricante/produtor e os revende ao varejista. Funciona como um intermediário. Para Parente (2000 apud CAMAROTTO, 2009), o atacado consiste no processo de vendas para clientes institucionais, que compram produtos e serviços para revendê-los, ou como insumos para suas atividades empresariais.

O setor atacadista é muito importante para o mercado brasileiro. Segundo a Associação Brasileira de Atacadistas e Distribuidores (ABAD), o faturamento anual de 2015 foi de $\mathrm{R} \$ 218,4$ bilhões, garantindo ao setor uma fatia de $50,6 \%$ do mercado nacional, atestando a importância da atuação do chamado Canal Indireto da indústria, que atende a todos os estabelecimentos varejistas que não têm volume de pedidos para adquirir produtos diretamente do fabricante.

A empresa, neste estudo denominada de ABC, foi fundada em 1998, para desempenhar o papel de atacadista/ distribuidora e operadora logística para a rede de lojas que se expandia pelo Brasil, a fim de obter ganhos de escala e processos altamente integrados com a rede e seus mais de 400 fornecedores.

A empresa funciona praticamente nos moldes de uma cooperativa, tendo um importante papel estratégico a desempenhar no desenvolvimento constante de suas tecnologias operacionais e negociais, em sintonia com o desempenho de rede.

Na classificação da ABAD, o centro de distribuição (CD) ABC enquadra-se como atacadista generalista, ou seja, compra e vende produtos de fornecedores da indústria sem vínculo de exclusividade ou território. O CD atende a uma rede de varejo fechada que, no caso, são lojas franqueadas de uma determinada marca.

A sede da empresa está localizada em Osasco (SP), em uma área de $1.400 \mathrm{~m}^{2}$, e conta com uma equipe de 49 colaboradores. Possui uma filial em Campo Grande (MS), em uma área de $1.431 \mathrm{~m}^{2}$ e 48 colaboradores. 
Atualmente, a empresa atende mais de 200 lojas, localizadas em 20 estados e no Distrito Federal.

Tanto o CD localizado no Estado de São Paulo (SP) quanto o de Mato Grosso do Sul (MS) oferecem às lojas a facilidade de adquirir mercadoria em módulos menores que os de fabricantes e outros atacados. Com isso, é possível operar com estoques menores, aliviando o caixa e obtendo menor ruptura de estoques. Outra vantagem é que a loja tem facilidade de realizar a logística reversa, ou seja, devolução de produtos ao centro de distribuição.

Além disso, a empresa oferece às lojas o pagamento da substituição tributária para o estado de destino. Isso evita que a mercadoria fique parada na barreira (para estados que possuem barreira tributária), facilitando o despacho da mercadoria e evitando falta de produtos na loja.

\subsection{Gestão e controle do estoque no atacado $A B C$}

A empresa utiliza um sistema próprio para armazenamento, movimentação e controle de estoques, nos moldes do Whare Management System (WMS), que significa sistema de gerenciamento de armazém. Tal sistema integra os processos de movimentação e armazenagem de um centro de distribuição. Segundo Tadeu (2010), é um software muito importante para o gerenciamento da empresa. As vantagens de um sistema WMS para a organização: aumento da acurácia das informações; aumento da velocidade das operações; e crescimento da produtividade do pessoal e dos equipamentos.

Para efetuar a reposição de mercadoria, o centro de distribuição ABC faz uso de um sistema híbrido entre o sistema do ponto de pedido e o sistema de reposição periódica. Os pedidos são feitos semanalmente, ou seja, em tempos fixos, porém também é analisado o ponto do pedido para sugerir a quantidade a ser adquirida. O próprio software emite um relatório com a sugestão de compras e a pessoa responsável tem autonomia para modificar as quantidades, para mais ou para menos.

Vale observar que não é utilizado o lote econômico de compras para minimizar o custo total do pedido. A cobertura dos estoques é medida e acompanhada. Nos últimos dois anos, observa-se um aumento significativo da cobertura média dos estoques, conforme mostra o gráfico:

Gráfico 1: Cobertura de estoque - em dias

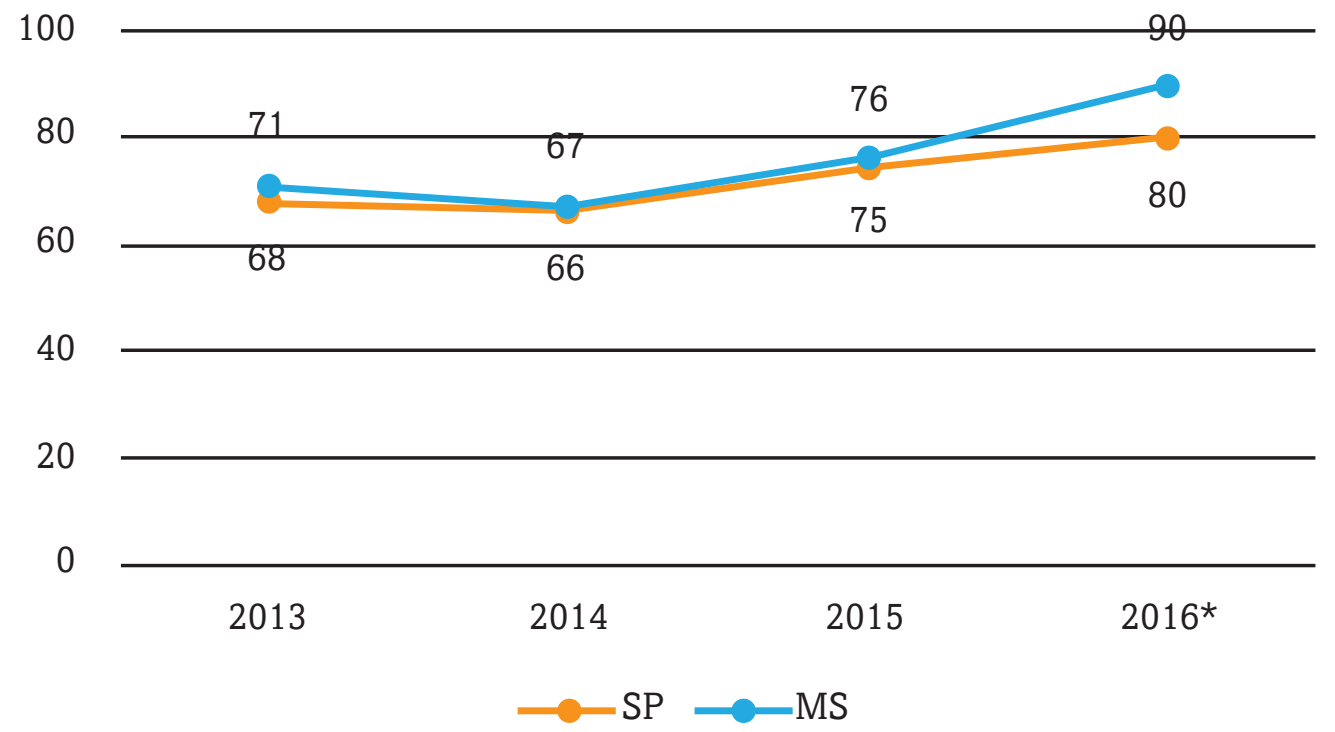

Fonte: Elaborado pelos autores

O Gráfico 1 demonstra que houve, principalmente nos últimos 2 anos, um aumento significativo da cobertura.

No Centro de Distribuição, existem vários produtos com data de validade que são passíveis de se deteriorar com o tempo, gerando prejuízos para a empresa. Na unidade de São Paulo, são 453 itens (8\% do total); na unidade do MS, o peso é menor, sendo 200 itens ( $3 \%$ do total).

Para evitar a deterioração, o sistema da empresa utiliza o método First Expire First Out (FEFO), que significa que o primeiro a vencer é o primeiro a sair. Este método garante que permaneçam no estoque os produtos com prazos de vencimento mais longos.

Neste sistema, cada produto que chega ao CD recebe uma etiqueta, onde consta o endereçamento do produto e sua data de vencimento. No momento da reposição do item, é sugerida a caixa com a data mais antiga.

A empresa tem por política interna não encaminhar mercadoria para as lojas com prazo menor que 90 dias do vencimento e as lojas têm um prazo para devolver ao CD mercadorias até 30 dias do vencimento; porém, as lojas não possuem o mesmo controle de vencimento que o $\mathrm{CD}$ possui. 
Figura 1: Etiqueta de identificação

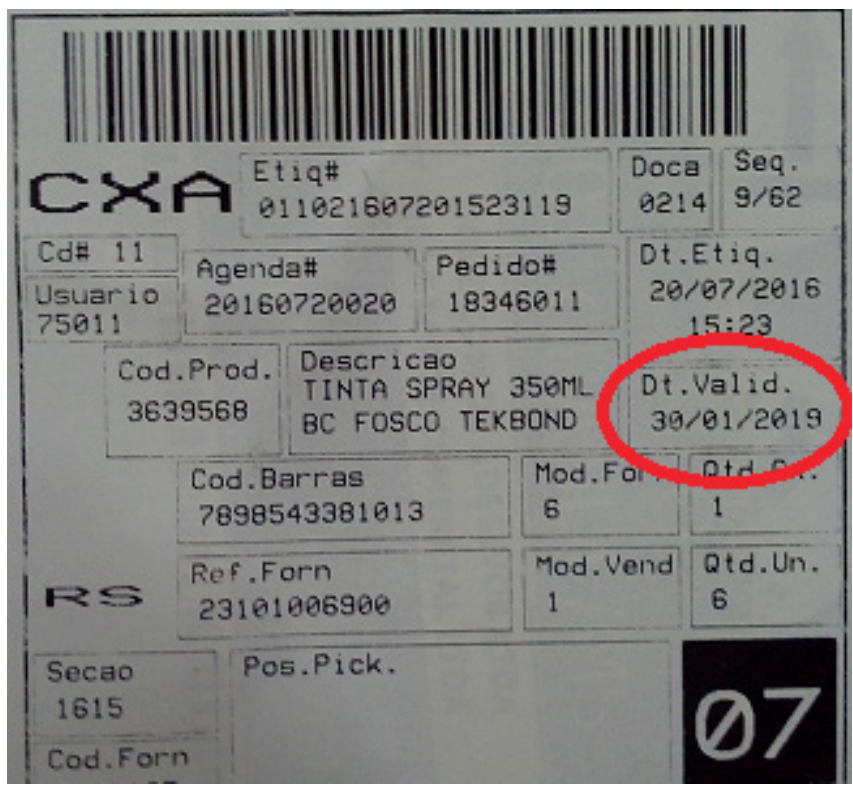

Fonte: Atacado ABC, 2016

\subsection{Procedimento atual em relação aos estoques obsoletos}

No final de cada mês, é feita uma cópia do banco de dados contendo a posição do estoque de cada filial. Nesta cópia constam informações item a item, como quantidade, custo, preço e estatísticas de venda, entre outras, como localização e movimentação de produtos. Os itens que estiverem com a classificação de inativos são elencados como candidatos a figurar como estoque obsoleto.

Atualmente, não existe uma regra específica escrita para definir o que é um produto inativo. Para selecionar itens nesta classificação, o procedimento seguido foi informado por um dos gerentes de negociação e compras. Segundo ele, a manutenção do mix de produtos é sugerida pelo comprador ao seu gerente, que o apresenta ao comitê semanalmente. Este comitê é formado pelos diretores de logística, produtos e operações e também pela gerência de produtos, comercial e de cadastros, além dos 4 compradores, totalizando 11 pessoas, sendo responsável por incluir, excluir e sugerir substituição de itens que componham o referido mix.

Nesta reunião, caso o produto esteja em estoque e possua baixo desempenho em vendas, a recomendação é realizar uma ação para a saída da mercadoria, como devolução, desconto ou liquidação. Se o item tem bom desempenho em vendas ou é indispensável para a diversificação do mix de produtos, é sugerido um similar para substituí-lo.

Após a inativação do item, é verificada a data da última entrada de cada um no estoque. Baseado no tempo que cada produto está sem dar entrada, é estabelecido um percentual aplicado sobre o valor do custo de aquisição, conforme Quadro 1. A soma destes valores compõe o valor da provisão para estoques obsoletos daquele período.

Quadro 1: Regra para o cálculo da provisão dos produtos obsoletos

\begin{tabular}{|cc|}
\hline Situação do Item Inativo & Valor da Provisão \\
1 - Sem entrada há mais de 60 dias & Custo $\times 20 \%$ \\
2 -Sem entrada há mais de 90 dias & Custo $\times 30 \%$ \\
3 - Sem entrada há mais de 120 dias & Custo $\times 50 \%$ \\
4 - Sem entrada há mais de 150 dias & Custo $\times 80 \%$ \\
5 - Sem entrada há mais de 180 dias & Custo $\times 100 \%$ \\
\hline
\end{tabular}

Fonte: Elaborado pelos autores

Constata-se que quanto maior o tempo em que o produto inativo está sem dar entrada no CD, maior é o percentual utilizado para a provisão. E que, após a inativação, o item pode entrar para a provisão em qualquer uma das cinco faixas. Vale ressaltar que, na regra atual, não é considerada a data da venda, mas apenas a data da última entrada. 


\subsection{Ações atuais de combate aos estoques obsoletos}

Há mais de dois anos a empresa faz um acompanhamento dos itens obsoletos, realizando diversas ações para que o estoque seja descartado. Uma das principais ações é a oferta de produtos a preços bastante reduzidos para a rede de lojas, a fim de incentivar a venda.

Os descontos aplicados sobre os preços dos produtos variam de $2 \%$ a $80 \%$, dependendo do tempo em que o produto estiver inativo, ou seja, quanto maior o tempo de inatividade, maior o desconto.

Recentemente, a empresa implantou um novo processo de comercialização dos itens considerados obsoletos. Por meio de um sistema on-line, as lojas poderão comprar tais itens via web. Tal processo visa dar maior dinâmica comercial à venda desses produtos e acelerar sua saída.

Caso o produto não tenha saída, mesmo com a campanha, é feita uma doação a entidades sem fins lucrativos, como a Associação de Pais e Amigos dos Excepcionais (APAE).

Do ponto de vista do gerente comercial do CD, entre as principais causas do estoque obsoleto podem-se citar:

a. Aumento da cobertura de estoque em função da sazonalidade de alguns produtos, férias coletivas da indústria e datas comemorativas.

b. Compra de produtos para atender o tabloide (jornal de oferta), sem comprometimento de compra da rede de lojas.

c. Troca de linha de produtos pelo fornecedor.

d. Baixa aderência da rede de lojas ao mix comum de produtos.

e. Falta de comprometimento da rede de lojas em comprar mercadorias do Atacado ABC.

f. Baixa capacidade da rede de lojas em absorver produtos em liquidação.

g. Disseminação de produtos similares de concorrentes na rede de lojas.

\subsection{Contabilização dos estoques obsoletos}

A empresa utiliza como critério de avaliação dos estoques o custo médio ponderado, que está respaldado pelo CPC 16.

De acordo com a responsável pela contabilidade da empresa, na contabilização dos estoques obsoletos é lançada uma provisão como redutora do ativo, em contrapartida, tendo uma despesa no resultado, não dedutível para fins fiscais.

Quando é realizada a venda de uma mercadoria que estava em provisão, é feita a reversão do valor provisionado, no período em que ocorreu a venda. $\mathrm{O}$ valor obtido com a venda é lançado como receita e o valor da baixa do estoque é o próprio custo da mercadoria. Esse procedimento está em desacordo com o CPC 16, pois, quando da venda, deve-se efetuar a baixa do estoque, juntamente com o ajuste da provisão para perda.

Não é praxe na empresa realizar a destruição da mercadoria que se tornou obsoleta, e sim realizar a doação destes materiais a entidades sem fins lucrativos, após esgotadas todas as tentativas de comercialização.

Neste caso, a empresa emite uma nota fiscal para dar cobertura à operação e faz uso de uma dedução na apuração do lucro e da base de cálculo da contribuição social sobre o lucro líquido (CSLL), nos termos do art. $13 \S 2^{\circ}$ da Lei $n^{\circ}$. 9.249/1995, que dispõe o seguinte:

$\S 1^{\circ}[\ldots] . \S 2^{\circ}$ Poderão ser deduzidas as seguintes doações: I - as de que trata a Lei $n^{\circ} 8.313$, de 23 de dezembro de 1991; II - as efetuadas às instituições de ensino e pesquisa cuja criação tenha sido autorizada por lei federal e que preencham os requisitos dos incisos I e II do art. 213 da Constituição Federal, até o limite de um e meio por cento do lucro operacional, antes de computada a sua dedução e a de que trata o inciso seguinte; III - as doações, até o limite de dois por cento do lucro operacional da pessoa jurídica, antes de computada a sua dedução, efetuadas a entidades civis, legalmente constituídas no Brasil, sem fins lucrativos, que prestem serviços gratuitos em benefício de empregados da pessoa jurídica doadora, e respectivos dependentes, ou em benefício da comunidade onde atuem, observadas as seguintes regras: a) as doações, quando em dinheiro, serão feitas mediante crédito em conta corrente bancária diretamente em nome da entidade beneficiária; b) a pessoa jurídica doadora manterá em arquivo, à disposição da fiscalização, declaração, segundo modelo aprovado pela Secretaria da Receita Federal, fornecida pela entidade beneficiária, em que esta se compromete a aplicar integralmente os recursos recebidos na realização de seus objetivos sociais, com identificação da pessoa física responsável pelo seu cumprimento, e a não distribuir lucros, bonificações ou vantagens a dirigentes, mantenedores ou associados, sob nenhuma forma ou pretexto.

É importante ressaltar que, caso a empresa opte por realizar a destruição de bens obsoletos, deve fazê-lo mediante laudo da autoridade fiscal. A legislação do imposto de renda, em seu artigo 291, trata das regras que envolvem as quebras e perdas anormais de estoque, que possibilitam a dedução como custo operacional do período, desde que obedecidas certas condições, in verbis: 
I - [...]. II - das quebras ou perdas de estoque por deterioração, obsolescência ou pela ocorrência de riscos não cobertos por seguros, desde que comprovadas: a) por laudo ou certificado de autoridade sanitária ou de segurança, que especifique e identifique as quantidades destruídas ou inutilizadas e as razões da providência; b) por certificado de autoridade competente, nos casos de incêndios, inundações ou outros eventos semelhantes; c) mediante laudo de autoridade fiscal chamada a certificar a destruição de bens obsoletos, invendáveis ou danificados, quando não houver valor residual apurável (BRASIL, Decreto 3.000/1999).

Por política da empresa, registrada em seu centro de documentação, as lojas podem devolver produtos com defeito de fabricação, produtos vencidos, prestes a vencer e produtos que compraram em excesso. No caso destes últimos, apenas aqueles itens que o CD comercializa, ou seja, que fazem parte do mix de produtos.

Os produtos que chegam com defeito são devolvidos ao fornecedor, que envia outro item em perfeito estado, concede abatimento na próxima fatura ou simplesmente quita o crédito gerado. Há poucos casos em que o fornecedor não aceita devolução. Nesta situação, dá-se quebra por meio de inventário rotativo.

\subsection{Análise dos resultados}

A empresa utiliza basicamente o conceito de produtos de baixo giro, como itens candidatos a se tornarem obsoletos, não observando a situação quando o valor realizável líquido for abaixo do custo de aquisição. Por este motivo, orienta-se esclarecer e difundir o conceito de produto obsoleto, que, segundo Femenick (2011), corresponde àqueles itens que perdem as condições de uso por serem arcaicos, antigos, fora de moda, ultrapassados.

Atualmente, a inativação de itens é uma decisão comercial. O item pode ser inativado por vários motivos, entre eles: produto fora de linha; demora na importação por parte do fornecedor; falta de condições comerciais para compra; baixo desempenho nas vendas, etc.

Ao aproveitar uma regra comercial para classificar os estoques obsoletos, poderá ocorrer distorção dos conceitos. Outra constatação é que um item, assim que se torna inativo, pode entrar em qualquer uma das cinco faixas da provisão, dificultando a realização de uma projeção destes estoques.

Atualmente, a empresa utiliza apenas o critério de tempo em que o produto fica sem entrada para selecioná-lo a candidato a obsoleto.

O ideal seria definir um prazo sem nenhuma movimentação, seja de entrada ou de saída, a partir do qual o item seria passível desta análise. Segundo Tomaselli (2007), em seu artigo, este período seria de 24 meses sem movimentação para um item se candidatar à obsolescência. Para Chaneski (2000 apud MOREIRA; IHY, 2006), em seu artigo, o prazo a ser fixado para este acompanhamento deve ser de 18 meses.

Cada empresa deve procurar implantar uma política, de acordo com suas características e necessidades. Em entrevista com o gerente do CD da filial MS, pôde-se verificar que o melhor prazo seria a partir de 12 meses, a fim de dar maior agilidade ao processo de saneamento do estoque.

Tomaselli (2007) sugere, ainda, como prática de prevenção, a definição de um processo de desativação de item. Conforme relatado pelo gerente de compras do $\mathrm{CD}$, atualmente, a empresa não possui uma regra clara para este quesito. O prazo que o produto permanece sem movimentação, seja de entrada, seja de saída, poderia ser um deles.

Após a definição dos itens candidatos à obsolescência, para uma melhor classificação destes, é recomendável segregá-los no estoque, conforme sugere Viana (2010): materiais a serem beneficiados; sucata; venda; e utilizar até esgotar.

Foi verificado que houve um aumento da cobertura dos estoques nos últimos dois anos. Este índice mostra quantos dias a empresa tem em estoque para cobrir as vendas. A empresa deve sempre monitorar este indicador, pois um nível de estoque elevado aumenta o risco com obsolescência e deterioração dos produtos.

No artigo intitulado "O impacto do planejamento e gerenciamento de estoque no resultado financeiro", Donato, Baron e Perez (2007) concluem que, devido à melhoria no giro dos estoques entre 2005 e 2006, que passou de 78 para 47 dias, houve melhoria em $0,71 \%$ do retorno sobre o investimento na empresa estudada.

Uma das conclusões de Wolf e Gomes (2015), em seu artigo sobre obsolescência de produtos em uma rede de farmácia, foi que uma das causas para sua ocorrência é a falta de consciência em relação ao método FEFO. Tal causa não foi encontrada no atacado $A B C$, pois este método está incorporado ao sistema de WMS da empresa.

Devido à dificuldade de estimar a perda item a item, no que se refere a estoque obsoleto, a contabilidade da empresa faz uso de uma provisão como redutora do ativo, sem dedução para fins fiscais, conforme indicado por Martins et al. (2013).

O uso de uma provisão para reduzir o ativo, realizado pela empresa, está previsto no CPC 16, o qual orienta que a prática de reduzir o valor de custo dos estoques (write down) para o valor realizável líquido é consistente com o ponto de vista de que os ativos não devem ser escriturados por quantias superiores àquelas que se espera serem realizadas com a sua venda ou uso.

Na doação de mercadorias a entidades sem fins lucrativos, a empresa utiliza a dedução no Imposto de Renda das Pessoas Jurídicas (IRPJ) e na base de cálculo da CSLL, conforme prevê o artigo 13 §2º da Lei nº. 9.249/1995. 


\section{CONSIDERAÇÕES FINAIS}

Este artigo procurou analisar os procedimentos adotados pela empresa objeto de estudo no tocante à provisão para estoques obsoletos e ao atendimento à legislação vigente.

Não foi possível precisar os impactos sobre o resultado da empresa, devido ao conceito atualmente utilizado para estoque obsoleto, que é mais propício para identificar produtos com baixo giro, e também pelo fato de uma decisão comercial na inativação de itens estar sendo usada para definir a provisão, além da falta de segregação e classificação no estoque de itens obsoletos.

Conclui-se que a empresa atende parcialmente à legislação no que se refere aos estoques obsoletos. Verificou-se que a legislação é atendida no que concerne à constituição da provisão, mesmo que feita por estimativa, e também quanto à dedução do imposto de renda e da base da CSLL, quando feitas doações a entidades sem fins lucrativos e limitada a $2 \%$ sobre o lucro do período, conforme artigo $13 \S 2^{\circ}$ da Lei ${ }^{\circ}$. 9.249/1995. Contudo, ao selecionar itens de baixo giro para compor a provisão, a legislação não é atendida, visto que, no conceito de itens obsoletos, são itens que perdem as condições de uso por serem arcaicos, antigos, fora de moda, ultrapassados.

Conforme apresentado, os descontos aplicados na venda dos itens obsoletos podem chegar até $80 \%$ do seu preço de venda atual. Considerando as margens apertadas deste segmento, conclui-se que a empresa tem perda com a venda do estoque obsoleto, uma vez que a maioria destes itens é vendida abaixo do preço de custo.

Apesar de não realizar a destruição de material considerado obsoleto, a empresa está ciente de que, neste caso, precisaria atender a legislação do imposto de renda em seu artigo 291, que exige a presença de uma autoridade fiscal para atestar o descarte.

Foi possível verificar que a empresa tem preocupação com a gestão e controle de estoques obsoletos, tanto que procura desenvolver várias ações corretivas. No entanto, no desenvolvimento do trabalho, foi possível identificar oportunidade de melhoria, principalmente em relação a ações preventivas, a fim de evitar a ocorrência de estoques obsoletos. Entre elas, encontram-se:

a. Aprimoramento do seu sistema de compras. Estudar possibilidade de implantação do lote econômico de compras, conjugado com o processo just in time.

b. Criação de regras claras e objetivas para o processo de desativação de itens, para que sua mensuração seja mais precisa.

c. Segregação do estoque obsoleto, conforme sugere Viana (2010), para que fique mais evidente quais são os itens que deverão ser trabalhados.

d. Inclusão do giro dos estoques em seus indicadores, como forma de mensurar o desempenho desse ativo tão importante.

e. Considerando que este estudo de caso não esgota todo o assunto, fica evidente que novas pesquisas precisam ser desenvolvidas para o aprofundamento da questão.

\section{REFERÊNCIAS}

ACCIOLY, Felipe; AYRES, Antônio de Pádua S.; SUCUPIRA, Cezar. Gestão de estoques. Rio de Janeiro: FGV, 2008.

ARNOLD, J. R. Tony. Administração de materiais. São Paulo: Atlas, 2009.

ASSOCIAÇÃO BRASILEIRA DE ATACADISTAS E DISTRIBUIDORES DE PRODUTOS INDUSTRIALIZADOS (ABAD). 2016. Dados do setor. Disponível em: <http://abad.com.br/ds_numeros_setor.php>. Acesso em: 25 ago. 2016.

BALLOU, Ronald H. Gerenciamento da cadeia de suprimentos/logistica empresarial. 5. ed. Porto Alegre: Bookman, 2006. 2007.

BOWERSOX, Donald J.; CLOSS, David J.; COOPER, M. Bixby. Gestão da cadeia de suprimentos e logistica. Rio de Janeiro: Elsevier,

BRASIL. Decreto n. 3.000, de 26 de março de 1999. Regulamenta a tributação, fiscalização, arrecadação e administração do Imposto de Renda e Proventos de Qualquer Natureza. Disponível em: <http://www.planalto.gov.br/ccivil_03/decreto/D3000.htm>. Acesso em: 10 abr. 2016.

BRASIL. Lei n. 9.249, de 26 de dezembro de 1995. Altera a legislação do imposto de renda das pessoas jurídicas, bem como da contribuição social sobre o lucro líquido, e dá outras providências. Disponível em: <http://www.planalto.gov.br/ccivil_03/leis/L9249. htm>. Acesso em: 21 abr. 2016.

CAMAROTTO, Márcio Roberto. Gestão de atacado e varejo. Curitiba: IESDE Brasil, 2009.

CATTI, James P. IFRS: guia de aplicação do valor justo. Porto Alegre: Bookman, 2013.

COMITÊ DE PRONUNCIAMENTOS CONTÁBEIS (CPC). CPC 16 - Estoques. Disponível em: <http://www.cpc.org.br/CPC/ Documentos-Emitidos/Pronunciamentos/Pronunciamento?Id=47>. Acesso em: fev. 2017.

DANNORITZER, Cosima. A história secreta da obsolescência programada: comprar, tirar, comprar. Disponível em: <https://youtu. be/o0k7UhDpOAo>. Acesso em: 5 set. 2016.

DEMO, Pedro. Introdução à metodologia da ciência. São Paulo: Atlas, 1985. 
DIAS, Marco Aurélio P. Administração de materiais: princípios, conceitos e gestão. São Paulo: Atlas, 2010.

DONATO, Felipe Alberto Simas; BARON, Guilherme Daudt; PEREZ, André da Costa. O impacto do planejamento e gerenciamento de estoque no resultado financeiro: estudo de caso Whirlpool S. A. - Unidade Embraco. In: ENCONTRO NACIONAL DE ENGENHARIA DE PRODUÇÃO, 27, 2007, Foz do Iguaçu. Anais... Foz do Iguaçu: ENEGEP, 2007. Disponível em: <http://www.abepro.org.br/ biblioteca/enegep2007_TR570428_9255.pdf>. Acesso em: 15 jul. 2016.

FEMENICK, Tomislav R. Controladoria e auditoria de estoques: para negócios globalizados. Curitiba: Juruá, 2011.

FIGUEIREDO, Kleber Fossati; FLEURY, Paulo Fernando; WANKE, Peter. (Orgs.). Logística empresarial: a perspectiva brasileira. São Paulo: Atlas, 2003.

GITMAN, Lawrence J. Principios de administração financeira. 10. ed. São Paulo: Pearson Adison Wesley, 2004.

HOUAISS, Antônio; VILLAR, Mauro de Salles. Minidicionário da língua portuguesa. 2. ed. Rio de Janeiro: Objetiva, 2004.

MARTINS, Eliseu; GELBKE, Ernesto Rubens; SANTOS, Ariovaldo dos; IUDÍCIBUS, Sérgio de. Manual de contabilidade societária (aplicável a todas as sociedades). 2. ed. São Paulo: Atlas, 2013.

MARTINS, Gilberto de Andrade; THEÓPHILO, Carlos Renato. Metodologia da investigação científica para ciências sociais aplicadas. São Paulo: Atlas, 2007.

MOREIRA, Daniel Augusto; IHY, Mauro Takeo. Gerenciamento do abastecimento de mercadorias: estudo de caso da reposição automática do Makro Atacadista S. A. Revista de Administração e Inovação, São Paulo, v. 3, n. 2, p. 5-22, 2006.

OLIVEIRA, Luís Martins de; PEREZ JR., José Hernandez; CHIEREGATO, Renato; BEZERRA, Marliete Gomes. Manual de contabilidade tributária. 12. ed. São Paulo: Atlas, 2013.

POZO, Hamilton. Administração de recursos materiais e patrimoniais: uma abordagem logística. 3. ed. São Paulo: Atlas, 2004.

ROSSETTI, Eraida Kliper; BARROS, Mauricio Sebastião de; TÓDERO, Mirele; DENICOL JÚNIOR, Silvio; CAMARGO, Maria Emilia. Sistema Just In Time: Conceitos imprescindíveis. Revista Qualit@s vol. 7, n. 2 (2008).

TADEU, Hugo Ferreira Braga (Org.). Gestão de estoques: fundamentos, modelos matemáticos e melhores práticas aplicadas. São Paulo: Cengage Learning, 2010.

TOMASELLI, Mauro. Estoques obsoletos: melhor sem eles. Revista Intelog, dez. 2007. Disponível em: <http://www.intelog.com. $\mathrm{br} /$ site/default.asp?TroncoID=907492\&SecaoID=508074\&SubsecaoID=627271\&Template=../artigosnoticias/user_exibir.asp\&I$\mathrm{D}=531144 \&$ Titulo=Estoques\%20obsoletos\%3A\%20melhor\%20sem\%20eles $>$. Acesso em: 30 jun. 2016.

VIANA, João José. Administração de materiais: um enfoque prático. São Paulo: Atlas, 2010.

WOLF, Wagner Rossales; GOMES, Leonardo de Carvalho. Estudo sobre obsolescência de produtos e principais causas: o caso de uma rede de farmácias do Rio Grande do Sul. Revista de Gestão UPDATE, Porto Alegre, n. 1, jan./jun. 2015. Disponível em: <http:// periodicos.faccentro.com.br/index.php/Update/article/view/49/32>. Acesso em: 17 ago. 2016

ZUFFO, João Antonio. A sociedade e a economia do novo milênio: os empregos e as empresas no turbulento alvorecer do século XXI. Barueri: Manole, 2004. 